Editorial

\title{
Sobre el cierre precoz de los ensayos clínicos
}

Los principales motivos que llevan a que un ensayo clínico se cierre antes de haber concluido la inclusión del número previsto de pacientes son dos. Uno es que el ritmo de inclusión de pacientes sea tan lento que se haga imposible alcanzar el número necesario en un tiempo prudencial. Y prolongar excesivamente un estudio hace que decaiga el interés por sacarlo adelante y por conocer los resultados ya que es posible que en ese tiempo haya quedado resuelta la pregunta que en su día se intentaba responder. El otro motivo que lleva a cerrar un ensayo sin haber alcanzado el número de pacientes es que a lo largo del estudio se evidencie un beneficio importante o un perjuicio severo en uno de los brazos del estudio.

El planteamiento de la investigación clínica es conservador. Un ejemplo es que el riesgo de tipo II (beta) de rechazar algo que es beneficioso que se admite en el diseño de los estudios es más alto que el de tipo I (alfa) de aceptar algo perjudicial. Y es este mismo planteamiento proteccionista el que pretende evitar que los que participan en ensayos clínicos sufran daños por estar incluidos en uno de los brazos de tratamiento. Suspender un ensayo porque en uno de los brazos se encuentra un daño o se niega un beneficio terapéutico no es un ataque a la metodología ni a la pureza de la investigación sino un modo de defender a los pacientes que participan en ese ensayo. Por así decir, es una manera de mostrar que para el investigador sigue valiendo más la seguridad y el bien del paciente real, presente e inmediato, que la conclusión y los objetivos del ensayo. No hay que olvidar que los criterios de defensa del paciente tienen su raíz en Nuremberg, donde fueron juzgados el nazismo y sus consecuencias, entre ellas los experimentos con personas que se llevaron a cabo en los campos de concentración. Además, sólo desde la defensa de los que participan en los ensayos es posible promover otros nuevos; ¿quién se animaría a entrar en un estudio si percibe que nadie va a velar por él, que nadie va a hacer la labor de centinela para avisar de posibles riesgos inesperados? Es razonable, por tanto, terminar precozmente un ensayo, al igual que lo es emplear el freno de emergencia en los trenes. Pero hacerlo es asumir una responsabilidad que sólo tiene sentido si responde a unos motivos serios y proporcionados.

Hay criterios metodológicos que procuran evidenciar "a tiempo" un posible perjuicio en los pacientes que entran en un ensayo clínico. Estos criterios reconocen que las valoraciones demasiado tempranas están expuestas a más desviaciones y que, además, la evaluación continua de los datos aumenta el riesgo de significaciones espurias. Por este motivo, sólo prestan atención a grandes diferencias que se vean avaladas por una significación estadística fuerte y que estén referidas a indicadores de beneficio fiables y a variables "duras", es decir, que no dependan de interpretaciones y que no se presten a sufrir grandes cambios relevantes con el seguimiento. Y aun así, la suspensión de un ensayo no debería fundamentarse en la frialdad de estos datos. Una decisión de tal peso debería estar matizada por una valoración personal, sensata y flexible, que tenga en cuenta los resultados en su contexto. Esta decisión debería ser consensuada por expertos independientes, que no estén vinculados con los promotores del ensayo, y "ciegos", es decir, que en la medida de lo posible ignoren la procedencia de los resultados. Y para favorecer que se pueda decidir con calma, a veces lo adecuado es suspender transitoriamente la inclusión de pacientes mientras se analizan los datos. Y es que sólo una valoración serena permite percibir que en ocasiones puede ser más prudente continuar el estudio, o continuarlo con condiciones, que suspenderlo definitivamente. 


\section{A. Sanz Rubiales}

Hay otra cuestión referida al cierre precoz de ensayos que es la perplejidad que produce el no haber podido terminar el ensayo y no saber si los datos se pueden extrapolar a lo que sería todo el estudio. Los resultados, aunque procedan de un estudio incompleto, siempre tienen valor. Pero hay que saber interpretarlos en su propio escenario, de acuerdo con el número y las características de los pacientes, las variables analizadas o la duración del seguimiento en relación con el que se preveía. Y es preciso ser prudente en las valoraciones porque en estos casos es fácil caer en cierto sesgo de publicación. Así, si el estudio se cierra precozmente porque se encuentra un gran beneficio en el brazo experimental, lo más probable que estos datos (preliminares) se publiquen pronto y en revistas de gran impacto. Sin embargo, si son unos resultados inesperadamente negativos en el brazo experimental los que llevan a cerrar precozmente el ensayo, es probable que los datos del seguimiento se obvien y que los resultados se oculten, de manera más o menos consciente, hasta que caigan en el olvido con el paso del tiempo. Pero esta ocultación, más o menos consciente, de los resultados negativos es una manera de cegar una fuente de evidencia, es decir, de conocimiento clínico. Y un modo de defraudar a aquellos enfermos que han decidido colaborar en el estudio con la intención de que lo que se pudiera aprender de su experiencia aumentara el conocimiento práctico de los profesionales y ayudara en un futuro a otros pacientes.

Dr. A. Sanz Rubiales Servicio de Oncología Hospital Clínico Universitario de Valladolid Valladolid (Espapña)

Correspondencia: Dr. A. Sanz Rubiales Oncología Médica Hospital Clínico Universitario C/ Ramón y Cajal, 3 E-47005 Valladolid asrubiales@hotmail.com 